\title{
Editorial
}

\section{Clinical and Epidemiological Characteristics of COVID-19 in a Multi-National Cohort in the Middle East}

The Kingdom of Bahrain, a country of around 1.5 million [1], reports as of February 2021, over 100,000 cases, and 420 deaths [2], ranking it as the 14th-highest country in terms of cases per 100,000 , but the 90th highest in deaths per 100,000 [3]. In terms of public health measures, Bahrain's Oxford COVID-19 Government Response Tracker (OxCGRT) Stringency level score peaked at 78.7 in late March/April. Enforced measures included school closure, cancellation of public events, use of face masks in public, international travel restrictions, comprehensive contact tracing, and a coordinated public campaign [4].

We conducted retrospective clinical and population-based analysis of COVID-19 cases reported from February 24, 2020-when the first case was diagnosed-to November 10, 2020. All cases were diagnosed as COVID-19 based on reverse transcriptasepolymerase chain reaction (RT-PCR) tests of nasopharyngeal samples. We report findings from one of the largest cohorts globally and the largest in the region to date. We hope this will diversify and address important gaps in the current literature, and guide and focus clinical and public health measures in the region.

The total number of positive cases identified was 83,811 (Table 1). The total number of tests conducted in the same time period was 1.84 million tests ( $4.5 \%$ of which were positive). Mean age of the individuals was 32.76 years $( \pm 16.37)$, with a male majority $(66.37 \%)$. Ninety-nine nationalities are reported in the cohort, with Bahrainis representing the majority (54.96\%). In terms of WHO Regions, the Eastern Mediterranean Region forms $63.67 \%$ of cases, followed by South-East Asia Region (33.36\%), Western Pacific Region (1.34\%), African Region (1.10\%), Region of the Americas $(0.28 \%)$, and European Region (0.24\%). Only $32.83 \%$ of the cohort was symptomatic. Children were more likely to present asymptomatically $(70.5 \%$ vs $66.3 \%) .54 .5 \%(n=45,891)$ were admitted to hospital and isolation facilities. $0.7 \%(n=623)$ required ICU admission. The overarching death rate is at $0.39 \%(n=331)$, with $97.1 \%$ of cases recovered/discharged.

In the subset analysis, we identified a total of 1792 patients hospitalized in COVID-19 hospitals. The mean age was $46.2( \pm 16.7)$, with a male majority (59.0\%). The majority (63.3\%) of the admitted patients presented with symptoms. Most common symptom was cough $(42 \%)$, followed by fever $(22.4 \%)$, dyspnea $(20.1 \%)$, myalgia (15.5\%), and chest pain (8.9\%). Other less commonly reported symptoms included diarrhea (5.8\%), nausea/vomiting (5.2\%), anosmia (3.1\%), and ageusia (3.0\%). The most common comorbidities
Table 1 Characteristics of COVID-19 cases and admitted patients in Bahrain, from February 24th to November 10th, 2020

\begin{tabular}{|c|c|}
\hline Characteristics & Values \\
\hline \multicolumn{2}{|l|}{ All COVID-19 cases $(n=83,811)$} \\
\hline \multicolumn{2}{|l|}{ Age } \\
\hline Mean - years & 32.76 \\
\hline \multicolumn{2}{|l|}{ Distribution - \% } \\
\hline $0-9$ & 10.50 \\
\hline $10-19$ & 9.81 \\
\hline $20-29$ & 19.71 \\
\hline $30-39$ & 27.79 \\
\hline $40-49$ & 17.11 \\
\hline $50-59$ & 9.69 \\
\hline $60-69$ & 3.83 \\
\hline $70-79$ & 1.12 \\
\hline $80-89$ & 0.39 \\
\hline $90-99$ & 0.06 \\
\hline $100+$ & 0.001 \\
\hline Male sex - \% & 66.37 \\
\hline \multicolumn{2}{|l|}{ Nationality - \% } \\
\hline Eastern Mediterranean Region & 63.67 \\
\hline South-East Asia Region & 33.36 \\
\hline Western Pacific Region & 1.34 \\
\hline African Region & 1.10 \\
\hline Region of the Americas & 0.28 \\
\hline European Region & 0.24 \\
\hline Symptomatic - \% & 32.83 \\
\hline \multicolumn{2}{|l|}{ Outcomes - \% (n) } \\
\hline Discharged & $97.14(81,418)$ \\
\hline Admitted to hospital/Isolation facility & $54.5(45,891)$ \\
\hline Active & $2.46(2062)$ \\
\hline Admitted to ICU & $0.7(623)$ \\
\hline Death & $0.39(331)$ \\
\hline \multicolumn{2}{|c|}{ Clinically admitted COVID-19 patients $(n=1792)$} \\
\hline Mean age - years & 45.93 \\
\hline Male sex - \% & 59.0 \\
\hline Bahraini Nationality - \% & 56.6 \\
\hline \multicolumn{2}{|l|}{ Smoking history - \% } \\
\hline Never smoked & 96.66 \\
\hline Former smoker & 1.32 \\
\hline Current smoker & 2.02 \\
\hline \multicolumn{2}{|l|}{ Symptoms - \% } \\
\hline Symptomatic & 63.3 \\
\hline Cough & 42.0 \\
\hline
\end{tabular}


Table 1 Characteristics of COVID-19 cases and admitted patients in Bahrain, from February 24th to November 10th, 2020-Continued

\begin{tabular}{|c|c|}
\hline Characteristics & Values \\
\hline Fever & 22.4 \\
\hline Dyspnea & 20.1 \\
\hline Myalgia & 15.5 \\
\hline Chest-pain & 8.9 \\
\hline Diarrhea & 5.8 \\
\hline Nausea/Vomiting & 5.2 \\
\hline Anosmia & 3.1 \\
\hline Ageusia & 3.0 \\
\hline \multicolumn{2}{|l|}{ Comorbidities - \% } \\
\hline Hypertension & 29.7 \\
\hline Diabetes mellitus & 28.9 \\
\hline Cardiovascular disease & 10.04 \\
\hline Glucose-6-phosphate dehydrogenase deficiency & 9.8 \\
\hline Asthma & 4.5 \\
\hline Chronic kidney disease & 4.4 \\
\hline Obesity & 3.24 \\
\hline Sickle cell disease & 2.1 \\
\hline Other lung diseases & 0.5 \\
\hline Chronic obstructive pulmonary disease & 0.4 \\
\hline \multicolumn{2}{|l|}{ Disease severity on admission - $\%(n)$} \\
\hline Admitted on room air & $88.11(1578)$ \\
\hline Admitted and on oxygen support & $11.28(202)$ \\
\hline Admitted and on NIV/HFNC & $0.45(8)$ \\
\hline Invasive ventilation & $0.17(3)$ \\
\hline \multicolumn{2}{|l|}{ Outcomes } \\
\hline Mean length of stay - days (IQR) & $10.56(6-13)$ \\
\hline Length of stay (survivors) - days (IQR) & $10.4(6-13)$ \\
\hline Length of stay (non-survivors) - days (IQR) & $14.4(5-19)$ \\
\hline Ventilated (non-invasive and invasive) - \% & 8.31 \\
\hline Intubated - \% & 2.62 \\
\hline Extubated - \% & 36.17 \\
\hline Died - \% & 3.29 \\
\hline
\end{tabular}

NIV, non-invasive ventilation; HFNC, high-flow nasal cannula.

included hypertension (29.7\%), diabetes mellitus (28.9\%), cardiovascular disease (10.04\%), glucose-6-phosphate dehydrogenase (G6PD) deficiency $(9.8 \%)$, asthma (4.5\%), chronic kidney disease (CKD) (4.4\%), obesity (3.24\%), sickle cell disease (2.1\%), and chronic obstructive pulmonary disease (COPD) (0.4\%). 2.2\% identified as current smokers, and $1.32 \%$ as ex-smokers.

$11.2 \%(n=202)$ of patients required supplemental oxygen on admission, $0.45 \%(n=8)$ required non-invasive ventilation/highflow nasal cannula, and $0.17 \%(n=3)$ required invasive ventilation. During hospital stay, we ventilated $8.31 \%$ of patients, and intubated $2.62 \%$. The overall mean length of stay was 10.56 days [Interquartile Range (IQR); 6-13]. For survivors, the mean length of stay was 10.4 (IQR; 6-13), compared to 14.4 (5-19) for non-survivors. The overall death rate was $3.29 \%$.

Logistic regression identified symptomatic status $(p<0.05)$, CKD, and hypertension $(p<0.01)$, as statistically significant predictors of severe respiratory disease (defined by ventilatory requirement).

Our study would be one of the largest cohorts from this region to confirm the association between certain comorbidities and disease severity, but that does not identify age as a risk factor [5]. Our cohort is one of the youngest reported in the literature [6,7]. We also report one of the highest proportions of asymptomatic cases [8], which may be related to the intensive wide screening policies. In terms of disease presentation, our cohort corroborates global findings, ranking cough, fever, and dyspnea as most common, albeit at a lower prevalence [6]. With regards to prevalence of comorbidities, and in line with reports from Iran and Kuwait, diabetes is a significantly prevalent comorbidity, unlike Western and East Asian cohorts $[6,7,9]$. Additionally, we report a higher prevalence of G6PD, and sickle cell disease compared to other cohorts, which is in line with this region's disease epidemiology [10].

\section{CONFLICTS OF INTEREST}

The authors declare they have no conflicts of interest.

\section{AUTHORS' CONTRIBUTION}

SIM drafted the manuscript. AA and AIA collected the data. SIM, AA and AIA analysed and interpreted the data. AA and MMA edited the manuscript. MMA supervised the project from conception and critically reviewed the manuscript. All authors contributed significantly to and approve of the final manuscript.

\section{FUNDING}

No financial support was provided.

\section{ETHICAL APPROVAL}

The data collected for the study was approved by the National COVID-19 Research and Ethics Committee.

\section{REFERENCES}

[1] Worldometers.info. Bahrain Population (LIVE). 2020. Available from: https://www.worldometers.info/world-population/bahrainpopulation/.

[2] Worldometers.info. Coronavirus Bahrain. 2020. Available from: https://www.worldometers.info/coronavirus/country/bahrain/.

[3] World Health Organisation. WHO Coronavirus Disease (COVID19) Dashboard. 2020. Available from: https://covid19.who.int/table.

[4] OxCGRT. Oxford COVID-19 Government Response Tracker. 2020. Available from: https://covidtracker.bsg.ox.ac.uk/stringency-scatter.

[5] Marin BG, Aghagoli G, Lavine K, Yang L, Siff EJ, Chiang SS, et al. Predictors of COVID-19 severity: a literature review. Rev Med Virol 2021;31;1-10.

[6] Nasiri MJ, Haddadi S, Tahvildari A, Farsi Y, Arbabi M, Hasanzadeh S, et al. COVID-19 clinical characteristics, and sex-specific risk of mortality: systematic review and meta-analysis. Front Med (Lausanne) 2020;7;459.

[7] Bajgain KT, Badal S, Bajgain BB, Santana MJ. Prevalence of comorbidities among individuals with COVID-19: a rapid review of current literature. Am J Infect Control 2021;49;238-46.

[8] He J, Guo Y, Mao R, Zhang J. Proportion of asymptomatic coronavirus disease 2019: a systematic review and meta-analysis. J Med Virol 2021;93;820-30. 
[9] AlmazeediS, Al-Youha S, Jamal MH, Al-Haddad M, Al-Muhaini A, Al-Ghimlas F, et al. Characteristics, risk factors and outcomes among the first consecutive 1096 patients diagnosed with COVID-19 in Kuwait. EClinicalMedicine 2020;24;100448.

Saad I. Mallah ${ }^{1}$, Abdulkarim Abdulrahman ${ }^{2,3}$, Abdulla I. Alawadhi ${ }^{2,4}$, Manaf M. AlQahtani ${ }^{1,2,4}$

${ }^{1}$ School of Medicine, Royal College of Surgeons in Ireland - Bahrain, Kingdom of Bahrain

${ }^{2}$ The National Taskforce for Combating the Coronavirus (COVID-19),

Kingdom of Bahrain

${ }^{3}$ Department of Cardiology, Mohammed Bin Khalifa Cardiac Centre,

Kingdom of Bahrain

${ }^{4}$ Department of Psychiatry, Bahrain Defence Force Hospital, Kingdom of

Bahrain

"Corresponding author. Email: drmanaf@gmail.com
[10] United Nations Department of Economic and Affairs (UN DESA). World Economic Situation and Prospects as of mid-2020. 2020. Available from: https://www.un.org/development/desa/dpad/wpcontent/uploads/sites/45/publication/WESP2020_MYU_Report.pdf. 